\title{
Individual Differences in Experiencing Occupational Stress-A Case Study on Nurses of Tamale Teaching Hospital (TTH)
}

\author{
Gifty Osei-Mireku, Xiangqian Wang, Jennifer Lartey, Francis Sarpong \\ School of Economics and Management, Anhui University of Science and Technology, Huainan, China \\ Email: giftymirekuosei.gom@gmail.com,xqwaust@163.com,je_naadu@yahoo.com,nanaipee@gmail.com
}

How to cite this paper: Osei-Mireku, G., Wang, X. Q., Lartey, J., \& Sarpong, F. (2020). Individual Differences in Experiencing Occupational Stress-A Case Study on Nurses of Tamale Teaching Hospital (TTH). Open Journal of Business and Management, 8, 1657-1673.

https://doi.org/10.4236/ojbm.2020.84105

Received: June 23, 2020

Accepted: July 21, 2020

Published: July 24, 2020

Copyright $\odot 2020$ by author(s) and Scientific Research Publishing Inc. This work is licensed under the Creative Commons Attribution International License (CC BY 4.0).

http://creativecommons.org/licenses/by/4.0/

(c) $\underset{\mathrm{By}}{\mathrm{i}}$ Open Access

\begin{abstract}
The concept of stress has been a long and lingering topic of research for ages. Stress in nurses in particular is no exception. Occupational stress is the threats of a job that workers face in the line of duty. However, one cannot separate the stress that already exists in their individual lives from those they face in line of duty. It is, therefore, undoubtedly possible that the level of occupational stress recorded may not be solely occupational problems. This paper seeks to find out the level of stress in nurses of TTH and whether individual differences affect the stress levels of nurses taking gender, age and marital status into consideration. The study used the Wieman Occupational stress scale to measure stress level; $\mathrm{t}$-test, One-Way and Three-Way ANOVA were used to determine the relationship between individual differences and levels of stress. Per the study, TTH records a mean score of 43.47 and an individual average score of 2.88 thus, $29 \%$ above normal stress level (baseline score: $33.75,2.25$ WOSS) indicating a generally high stress level among the nurses. A sample size of 452 revealed that there is a significant association between stress and gender $(p=0.041)$ and male nurses were more stressed than female nurses. There was also a significant association between age and level of stress $(p=0.00)$, where younger nurses (20 - 30 years) were more stressed than older nurses (30 - 40 years and above 40 years). However, no significant association was found between marital status and occupational stress. Although combined together, these three variables do not affect stress, the results for individual variables report the need for management and researchers to integrate individual differences when investigating or managing occupational stress.
\end{abstract}

\section{Keywords}

Occupational Stress, Tamale Teaching Hospital (TTH), Gender, Age, Marital 
Status

\section{Introduction}

Stress is a feeling of emotional and physical tension in reaction to challenge or demand (Mediline Plus, 2020). Stress is a natural phenomenon. Occupational stress is of key interest to employers because of the known adverse effects on employee performance, productivity, job satisfaction and health as a whole (Moustaka \& Constantinidis, 2010). It is therefore the ongoing or progressing stress an employee experiences due to the responsibility and other pressures at the workplace (Bamboo, 2020). The nursing profession is known to be stressful throughout the world and has detrimental effects on the physical and psychological well-being of nurses' health (Onasoga et al., 2013). In the most recent pandemic outbreak, novel coronavirus disease 2019 (nCOVID-19 or COVID-19), the healthcare workers, mainly nurses have been the most at risk being at the forefront of the disease control across the world (Huang et al., 2020). Stress is normal, everyone feels stress related to work, family, decisions, your future, and more, both physical and mental. It is caused by major life events such as illness, the death of a loved one, a change in responsibilities or expectations at work, and job promotion, loss, or changes. Major workplace and personal stress are inevitable (Heathfied, 2019); however if uncontrolled, it can lead to detrimental effects on the individual and the organization.

The Regus Group reports that stress in workplaces is rising with 6 in 10 workers in major global economies experiencing increased workplace stress. The Labor Force Survey of the UK revealed the total number of work-related stress, depression, or anxiety in $2014 / 15$ was 440,000 cases, with a prevalence of 1380 per 100,000 workers. The incidence of work-related stress, depression or anxiety in the same period was 740 per 100,000 workers (Health and Safety Executive, 2015).

\section{Stress in Nurses}

Countless research has shown that nurses are highly stressed (Mudallal et al., 2017). Hector et al. measured level of stress among PTSD nurses in 2018 and recorded high levels of emotional exhaustion. In a study of occupational stress in healthcare workers in the Goaso Government Hospital in Ghana, Tanko Iddi Abdulai observed above average levels of occupational stress with nurses showing the highest levels (Abdulai, 2011). A similar study done in 2018 comparing two hospitals in Ghana showed that, levels of occupational health hazards was high in Accra and Pantang hospitals (i.e. 92\% and 81\% respectively) (Alhassan \& AduPoku, 2018).

Occupational stress is not generated in a vacuum. Factors in the workplace contribute to the levels of stress that workers feel known as stressors (Masa'Deh 
et al., 2018). Carr et al. (2011) stated that, the three main areas that influence the level of stress felt in the workplace are Job demands (the intrinsic task requirements, the uncertainty, time pressure, and difficulty of work. that is, what it takes to get the job completely done, whether the doer has the capacity or not), Individual differences (the components of heredity, age, gender marital status and environment that makes people different) and Social demands (which is how an individual perceives his or her social-network support needs). Jourdain \& Chênevert (2010) are also of the view that the most serious stressors in healthcare context are organizational factors, which are classified into job demands and Resource deficiency. Abdulai (2011) also confirms this factor as a contributor to job stress. While the above causes of stress are to a certain degree related to all jobs, the nursing profession has them to an above average level. Nursing is unarguably a stressful profession, with work constantly revolving around death, threatening disease, illness, lifelong disability, injury, pain, suffering, and misery (Mark \& Smith, 2012). Stressed nurses have high tendency to render poor services and can even put other's lives at risk (Park \& Ahn, 2015). In recent studies on nurses' stress, it was reported that, emotional exhaustion, depersonalization and lack of personal accomplishment were main contributing factors to stress (Urquiza et al., 2017, Reyes et al., 2018, Fuente et al., 2018, Hernández et al., 2018).

\subsection{Individual Differences and Stress}

Occupational stress has been proven to have its main source from work environment but Socio-demographic factors such as sex, age, and work experience could be correlated to work-related stress and burnout among professionals in medical settings (Urquiza et al., 2016; Duarte \& Pinto-Gouveia, 2017; Taleghani et al., 2017). Research done on nurse's stress in Ghana have not considered the role that individual differences can play in the levels of stress. This paper therefore seeks to fill this gap and proof the importance of accessing these factors to know how best managing stress in the nurses can be most effective. Individual differences here refer to the socio-demographic factors that the nurses possess and make them unique from each other and do not have any relation with their work. They may include personality type, race, culture, age, sex, etc. This paper only looks at three differences-age, gender, and marital status. These differences affect perceptions and interpretations of events around a person and they contribute to their experience of stress, and their decision of what to do to deal with stress. Some literature suggests that, these three factors have no association with the level of stress experienced by nurses (Khosravi \& Kasaeiyan, 2019). While others saw a significant association between work stress and all three factors (Siddiqui et al., 2017; Nyamwata et al., 2017). Several research that has been done also have realized associations between some of the three factors and not others. Example, some literature suggests that no relationship exists between gender and occupational stress, but there is an association with age (Sharafi et 
al., 2018; Yim et al., 2017; Trousselard et al., 2015).

\subsection{Gender and Stress}

Soltan's study reports that, Gender had no significant association to the mean score of work stress $(P>0.05)$ (Soltan et al., 2020). These results suggest that, occupational stress is a transgender phenomenon and can affect anyone, male or female (Faraji et al., 2019) whereas Deguchi and Quian disagrees and thinks Gender differences need to be considered when developing stress prevention strategies (Deguchi et al., 2018; Qian et al., 2019). A general possibility exists in older literature in which females experience higher levels of occupational stress regarding gender-specific stressors and have different ways of interpreting and dealing with problems related to their work environment. Men have better response to stress and coping than women and Baruch reported women are more prone to stressors than men (Baruch et al., 2003). Women experience higher levels of occupational stress than men (Shukla \& Srivastava, 2016; Nam et al., 2018; Hipp et al., 2015). Women have 40\% higher stress than men (American Psychological Association (APA), 2010). Contrary to this, some researchers are of the view that, men experience higher levels of stress than women (Lee \& Cho, 2016). This is due to their personal and professional responsibilities (Mudallal et al., 2017). In Ghana, the adult man has the pressure from society to be successful financially, professionally, and socially and is in constant competition to be the best. The psychological stress already exists by virtue of their gender. Jobs with more men result in higher levels of unpleasantness and stress in the men, and lower levels of meaningfulness at work for women (Qian et al., 2019).

\subsection{Age and Stress}

Age comes with experience, hence work experience. Literature reveals that older or more experienced employees record lower levels of stress as compared to younger and less experienced once. The ability to handle stress associated with job and organization was found to increase with age (experience) (Ang et al., 2016; Shukla \& Srivastava, 2016). Employees who are less than 40 years old experience the highest levels of stress (Faraji et al., 2019). Dua explains this concept that, older employees have reached a stage where career development is no longer their major concern, and hence a number of job characteristics which may cause stress to younger staff, who have their career ahead of them, do not cause stress to older staff. Metin in his research realized that, older nurses have a high risk of anxiety (Picakciefe et al., 2015). Some researchers did not record any significant association between age and stress (Sabzi et al., 2017; Romano et al., 2015).

\subsection{Marital Status and Stress}

Although there has not been enough research done on marriage and job stress among nurses, the few suggest that there is no a significant association between marital status and job stress (Amazue \& Onyishi, 2016; Cheng et al., 2016). Oth- 
ers disagree and believe that there is a significant association between stress and marital status, thus the marital status of an individual can be a source of stress due to the responsibility and pressure on an individual (Nyamwata et al., 2017). Married workers are more stressed than unmarried workers (Ghafoor et al., 2020; Liu et al., 2015; APA, 2010) and Huda reports that, married nurses have a $74.6 \%$ of work related stress (WRS), Yet another school of thought is of the view that, single or unmarried workers are more stress than the married (Howells et al., 2020) and unmarried nurses are at higher risk of heart diseases and cancer (Siddiqui et al., 2017; Wang et al., 2020; Fuente et al., 2018a) even a category of singles (windowed or divorced) have a significantly higher stress level than the married due to emotional distress (Young Kim, 2017). This is because married men tend to have a friend to aid in stress relief and women tend to have a provider to aid in relief (Kohen \& Kaplan, 2016). Being married and having a stable partner is attrited to low stress (Franca et al., 2012). John Gottman said that, it isn't just being married that is the advantage. It is the quality of the marriage; whether couples are married or happy in the marriage. He said that people and children in troubled marriages fare as badly in terms of health status as are divorced people (Gottman, 1999). This means that, the difference in marital status may not be a variable enough to analyze occupational stress. The quality of the marriage needs to be considered as a scalar to calculate stress.

\section{Statement of Problem}

Studies on job stress, especially among health workers in Ghana have centered on the Southern part of the country, excluding the Northern Region which is the largest of the ten regions in Ghana, covering $31 \%$ of the land area of the country. The North is getting more populated and busier and as such jobs can be expected to be getting more demanding. One institution that can be expected to pose significant levels of stress is the Tamale Teaching Hospital (TTH) because it has become priority referral center in the North. Most of the studies done occupational stress in Ghana focuses on causes, effects, coping strategies and management of stress but fail to adjust for possible confounders (such as gender, age, marital status, financial stability etc.) in the measurement of job stressors. It is, therefore, not certain if the stress levels were purely attributable to occupational stressors or if the nurses were responding to occupational stress with other influences.

\section{Objectives}

The purpose of this study is to:

Measure the level of job stress in the nurses of the Tamale Teaching Hospital;

Study and analyze the impact of individual differences on the level of stress taking into consideration gender, age, and marital status.

Hypothesis

H1: Female nurses do not record higher stress levels than male nurses 
H2: Married nurses do not record higher levels of stress than single nurses

H3: Younger nurses do not record higher levels of stress than older nurses

\section{Methodology}

This study included all nurses working at the Tamale Teaching Hospital. Yamane (1967) sample size formula was used, and the convenient sampling technique was used to select the sample of 476 in the study out of a population of 834 nurses. This procedure was relatively easier and gives an almost accurate representation of the population. This includes all nurses from all the four main departments of the hospital: Medicine, Obstetrics and Gynecology, Surgical and Pediatrics department. A total of 476 but 452 were retrieved.

Yamane 1967 formula:

$$
n=\frac{N}{1+834(0.03)^{2}}=476.41 \approx 476
$$

where

$$
\begin{aligned}
& n=\text { sample size } \\
& N=\text { Population of the study } \\
& e=\text { error estimate at } 3 \%(0.03) \text { and } 1=\text { constant }
\end{aligned}
$$

The standardized instrument utilized was the Weiman Occupational Stress Scale which was used to establish a baseline score for the participants in the study. The scale is a fifteen question Likert-type instrument that measures work related stress. Answers on the scale range from 1 - 5 points, with $1=$ strongly disagree, 2 = disagree, 3 = sometimes, 4 = agree, and $5=$ strongly agree. It is aimed at determining the level of occupational stress among nurses in the hospital. The questionnaire was structured in line with occupational stress indicators and applied in the data collection through self-administration. It is scored by adding together the total number of points for the 15 questions and then dividing the sum by the number 15 . The range that can be scored by a subject is a maximum of 75 and a minimum of 15 . The greater the score, the more occupational stress is being reported. Applying the scale to a wide variety of occupations, Weiman and other researchers established a baseline mean score of 33.75 and individual average of 2.25.

Statistical analysis: data were presented as frequencies (F), percentages (\%), means and Standard deviations (SD) and were analyzed by SPSS statistical package version 25. Student's t-test is a test of significance used for comparison of quantitative variables between two groups of normally distributed data. Analysis of the variance (ANOVA) test was used for comparison of quantitative variables between more than two groups of normally distributed data with Turkey test as post Hoc test.

The t-test was used to test for association between "gender and stress" and "age and stress". One-way ANOVA was done to derive the association between stress and age, and three-way ANOVA was test was carried out comparing the 
association of all three variables and stress levels.

\section{Results}

\subsection{Demographic Characteristics}

The demographic data covers the gender, marital status, age, department and hours worked in a week of the respondents. Table 1 reveals the demographic data of respondents and corresponding percentages. A total of 141 (31.2\%) males and $311(68.8 \%)$ female nurses were involved in the study. In terms of marital status, 218 (48.2\%) of the nurses were not married and 234 (51.8\%) were single. There was no distinction made in whether the single nurses were divorced or widowed because the study is focused on workers within the scope of marriage and those outside it. The sample of nurses was randomly selected from four main departments-170 from Medicine, 125 from Surgery, 65 from Obstetrics and Gynecology and 92 from Pediatrics, representing 37.6\%, 27.7\%, 14.4\% and $20.4 \%$ of the sample, respectively. These departments can be said to be some of the busiest in the hospital. Depending on the demand of patients at the hospital, 106 nurses reported to work for less than 40 hours a week, 309 work their shifts between 40 to 55 hours and 37 works above 56 hours, thus, $23.5 \%, 68.4 \%$ and $8.2 \%$ respectively.

\subsection{Main Results}

This section deals with the results and discussion based on the data collected from the field. The data is used to answer the research question and hypothesis.

\section{Research Question One: What Is the Level of Stress of Nurses of The Tamale Teaching Hospital?}

The level of stress was computed for each respondent in the Tamale teaching hospital (TTH). From the data collected, the study found that the general average stress level of nurses in the hospital was a mean score of 43.44 and an individual average score of 2.89 . This means that there is a significantly high level of stress among the nurses as represented in Table 2. Comparing it to the standard mean score of 33.75 and individual average of 2.25 established by the WOSS, the survey response shows that, TTH nurses are approximately $29 \%$ and $28 \%$ above normal stress level, respectively. This level of stress was reported to have been caused by work overload, lack of staff and inadequate resources for work.

Research Question Two: What Is the Impact of Individual Differences on the Level of Stress Taking into Consideration Gender, Age, and Marital Status?

Table 3 summarizes the impact of age, gender, and marital status on the level of stress of the nurses in TTH.

A three-way between groups ANOVA was used to examine the main effects of individual differences on the level of stress taking into consideration gender, age, and marital status. Table 3 shows the mean number of individual differences of 
Table 1. Demographic data of respondents.

\begin{tabular}{ccc}
\hline Variable & Sub-scale & $\mathrm{F}(\%)$ \\
\hline Gender & Male & $141(31.2)$ \\
Marital status & Female & $311(68.8)$ \\
& Single & $218(48.2)$ \\
Mge & Married & $241(54.6)$ \\
& 20 to 30 years & $216(47.8)$ \\
Department & Above 40 years & $129(28.5)$ \\
& Medicine & $107(23.7)$ \\
& Surgical & $169(36.7)$ \\
& Obstetrics and Gynecology & $125(27.2)$ \\
Hours Worked in a Week & Pediatrics & $65(14.1)$ \\
& Less than 40 hours & $91(22.0)$ \\
& 40 - 55 hours & $306(23.5)$ \\
& Above 56 hours & $37(8.2)$ \\
\hline
\end{tabular}

Table 2. Level of stress among TTH nurses.

\begin{tabular}{ccc}
\hline Stress Level & Stress score & WOSS Standard \\
\hline General Stress & 43.47 & 33.75 \\
Individual stress & 2.88 & 2.25 \\
\hline
\end{tabular}

Table 3. Impact of individual differences on the level of stress of nurses.

\begin{tabular}{|c|c|c|c|c|c|}
\hline \multicolumn{6}{|c|}{ Tests of Between-Subjects Effects } \\
\hline Source & $\begin{array}{c}\text { Type III Sum } \\
\text { of Squares }\end{array}$ & df & Mean Square & $\mathrm{F}$ & Sig. \\
\hline Corrected Model & $1355.011^{\mathrm{a}}$ & 11 & 123.183 & 2.813 & 0.001 \\
\hline Intercept & $625,796.687$ & 1 & $625,796.687$ & $14,289.408$ & 0.000 \\
\hline GENDER & 193.604 & 1 & 193.604 & 4.421 & 0.036 \\
\hline MARITAL_STATUS & 8.790 & 1 & 8.790 & 0.201 & 0.654 \\
\hline AGE & 601.296 & 2 & 300.648 & 6.865 & 0.001 \\
\hline GENDER ${ }^{\star}$ MARITAL_STATUS & 94.793 & 1 & 94.793 & 2.164 & 0.042 \\
\hline $\mathrm{GENDER}^{\star} \mathrm{AGE}$ & 137.614 & 2 & 68.807 & 1.571 & 0.209 \\
\hline MARITAL_STATUS*AGE & 22.822 & 2 & 11.411 & 0.261 & 0.771 \\
\hline GENDER $^{\star}$ MARITAL_STATUS ${ }^{\star}$ AGE & 39.565 & 2 & 19.783 & 0.452 & 0.637 \\
\hline Error & $19,269.556$ & 440 & 43.794 & & \\
\hline Total & $874,704.000$ & 452 & & & \\
\hline Corrected Total & $20,624.566$ & 451 & & & \\
\hline
\end{tabular}

${ }^{\mathrm{a}} \mathrm{R}$ Squared $=0.066$ (Adjusted R Squared $=0.042$ ). 
nurses. The data revealed that there was no significant three-way interaction, $\mathrm{F}$ $(2,440)=0.452, p<0.637, \mathrm{MSE}=43.794$. Examination of the cell means (using LSDmmd $=1.95$ ) reveals that, as hypothesized, the pattern of this interaction was that the combination of age, marital status and ages of nurses showed no preference in terms of having effect on stress level of nurses. There was also a no significant 2-way interaction of marital status and age, F $(2,440)=0.261, p<$ $0.771, \mathrm{MSE}=11.411$. The pattern of this interaction (using LSDmmd $=1.12$ ) was that, as hypothesized indicate that the combination of marital status and age of nurses does not have any effect on the stress level of nurses. Again, there was no significant 2-way interaction of gender and age, $\mathrm{F}(2,440)=1.571, p<0.209$, $\mathrm{MSE}=68.807$. However, there was a significant 2-way interaction of gender and marital status, $\mathrm{F}(1,440)=2.164, p<0.042, \mathrm{MSE}=94.793$. This indicates that combining gender of nurses together with their marital status can cause stress at the workplace depending on the situation a nurse finds him or herself.

There was a main effect for gender and age on the level of stress at the hospital as shown in respective $\mathrm{F}(1,440)=4.421, p<0.036)$ for gender of nurses and $\mathrm{F}$ $(1,440)=6.865, p<0.001)$. As hypothesized, age and gender have greater influence preferred to marital status in determining their effect on stress level (based on LSD mmd $=0.97$ ).

Hypothesis One (H1): Female Nurses do not Record Higher Stress Levels than Male Nurses

The independent sample t-test was used to test the difference in gender of nurses and level of stress. The results have been summarized in Table 4.

From Table 4, the results show that there is a significant difference between male nurses $(44.43, \mathrm{SD}=6.57)$ and female nurses $(43.33, \mathrm{SD}=6.81)$; $\mathrm{t}(450)=$ 2.047, $p=0.041$, (two-tailed). This means that the null hypothesis is rejected. Therefore, there is difference in the level of stress between male and female nurses in Tamale Teaching Hospital. It can be concluded that male nurses record higher levels of stress than female nurses.

Hypothesis Two (H2): Married Nurses Do Not Record Higher Levels of Stress than Single Nurses

Analysis of data collected also found that there is no significant difference between the level of stress of single nurses $(M=43.23, S D=7.19)$ and married nurses $(\mathrm{M}=43.69, \mathrm{SD}=6.34) ; \mathrm{t}(450)=-7.72, p=0.47$ (two-tailed). This indicates that we fail to reject the null hypothesis that married nurses do no record higher level of stress than single nurses. This means that there is no association of differences between single and married nurses with respect to stress levels. Hence, both married and single nurses in TTH experience or exhibit the same level of stress. The results are presented in Table 5.

Hypothesis Three: Younger Nurses Do Not Record Higher Levels of Stress than Older Nurses

A one-way ANOVA was adopted in testing the difference between the ages of nurses and level of stress in the Tamale Teaching Hospital. The results are shown in Table 6. 
Table 4. Difference between male and female nurses and level of stress.

\begin{tabular}{ccccccr}
\hline Variable & Gender & Mean & SD & t-value & Df & $p$-value \\
\hline Students' Academic & Male & 44.43 & 6.57 & 2.047 & 450 & 0.041 \\
Performance & Female & 43.33 & 6.81 & & & \\
\hline
\end{tabular}

$p<0.05$.

Table 5. Difference between married and single nurses and level of stress.

\begin{tabular}{ccccccc}
\hline Variable & Gender & Mean & SD & t-value & Df & $p$-value \\
\hline Students' Academic & Single & 43.23 & 7.19 & -7.27 & 450 & 0.47 \\
Performance & Married & 43.69 & 6.34 & & \\
\hline$p$
\end{tabular}

Table 6. ANOVA of the difference between the ages of nurses and level of stress.

\begin{tabular}{cccccc}
\hline & Sum of Squares & df & Mean Square & F & Sig. \\
\hline Between Groups & 797.255 & 2 & 398.628 & 9.027 & 0.000 \\
Within Groups & $19,827.311$ & 449 & 44.159 & & \\
Total & $20,624.566$ & 451 & & & \\
\hline
\end{tabular}

A one-way ANOVA between subjects was conducted to compare the ages of nurses and the level of stress in the Tamale Teaching Hospital. There was a significant effect of ages of nurses on stress levels at the $p<0.05$ level for the three differences in age $[\mathrm{F}(2,449)=9.027, p=0.00]$ (Table 6). Post hoc comparison using the Turkey HSD test indicated that the mean score for nurses between the ages of 20 and $30(\mathrm{M}=44.61, \mathrm{SD}=6.22)$, between the ages of 31 and $40,(\mathrm{M}=$ 43.38, $\mathrm{SD}=5.96)$, and ages above $40(\mathrm{M}=41.27, \mathrm{SD}=8.09)$ as shown in Table 7 , was significantly different from stress level of nurses. This means that the age of the nurses influences their level of stress. Therefore, nurses between the ages of 20 and 30 are more stressed than those between 30 and 40 and above 40 .

\section{Discussion}

This paper sought to analyze and determine whether the levels of stress experienced by nurses are influenced by their socio-demographic characters considering age, marital status, and gender. Nursing is seen as a female dominant profession by social standards and Florence Nightingale explains it to be so because it is an extension of the woman's duty of care and nurturing from home (Nursing Time, 2008; Bublitz et al., 2015). This explains why majority of nurses are females even in TTH.

This study confirms that, occupational stress in nurses is above average levels in Ghana (Kokoroko \& Sanda, 2019). A similar result was recorded in Saint Dominic's Hospital-Akwatia in Ghana showing a $10 \%$ above average stress level of the WOSS standard (total score of 37.01 and 2.47 individual score) 
Table 7. Descriptive.

\begin{tabular}{ccccccc}
\hline & & & & & \multicolumn{2}{c}{$\begin{array}{c}95 \% \text { Confidence } \\
\text { Interval for Mean }\end{array}$} \\
\cline { 5 - 7 } & & & Mean & Std. Deviation Std. Error & \multicolumn{2}{c}{\begin{tabular}{c} 
Lower Bound Upper Bound \\
\cline { 5 - 7 }
\end{tabular}} \\
Age between 20 and 30 & 216 & 44.6065 & 6.22282 & 0.42341 & 43.7719 & 45.4410 \\
Between 30 and 40 & 129 & 43.3876 & 5.96384 & 0.52509 & 42.3486 & 44.4266 \\
Above 40 & 107 & 41.2710 & 8.09678 & 0.78275 & 39.7192 & 42.8229 \\
Total & 452 & 43.4690 & 6.76245 & 0.31808 & 42.8439 & 44.0941 \\
\hline
\end{tabular}

(Adzakpah et al., 2016). Inadequate staff, insufficient resources and work overload were the top three contributors of the high stress levels. Researchers like Masa'Deh et al. (2018), Ebrahimi \& Kargar (2018), Alomani (2016), and Adzakpah et al. (2016) also recorded workload, and inadequate resources as the main sources of stress in nurses. Nurses face stress right from college into practice. It is therefore not surprising that the job stress levels of nurses are relatively high across hospitals (Cestari et al., 2017; Kashif \& Khan, 2016).

Within the studied groups, there was a significant difference in stress levels between males and females. Confirming that, there is a significant association between gender and stress levels (Ezenwaji et al., 2019; Nyamwata et al., 2017). Although a significant association was found in these researches, there were discrepancies in the level of stress exhibited by male and female nurses. While some concluded that, female nurses rated a higher general stress score (Dab et al., 2015; Biswas \& Naidu, 2019; Makhaita et al., 2014; Caruso et al., 2017), others reported a higher stress level in male workers (Picakciefe et al., 2015; Fuente et al., 2018b; Lee \& Cho, 2016). Female nurses are more stressed because, a greater number of the population of women and children visit the hospital on a daily basis and require the services of female nurses, who also have family and home responsibilities more than males (Jacobs et al., 2016). Sayeed suggests that, both males and females have a moderate level of stress although females have a slightly higher level (Sayeed et al., 2017).

Although these results give different reports on which gender may be more stressed, they are proof of the fact that, stress levels are not solely caused by occupational stressors but are also affected by other factors. Therefore, gender needs to be considered when measuring the level of stress in organizations. Although the difference in work according to sex has decreased in many developed countries, it is still obvious that there is still gender specific role in workplace, which has an impact on occupational stress (Young Kim, 2017).

The result on marital status has revealed that marital status should not be considered when calculating or analyzing stress levels in nurses because there is no significant association between marital status and occupational stress. This result confirms the results of Amazue \& Onyishi (2016), Cheng et al. (2016), Khosravi \& Kasaeiyan (2019). Contrary to this, Ghafoor et al. (2020) believe that 
there is a significant association between stress and marital status, saying married workers are more stressed than singles (Makhaita et al., 2014).

In a book written by Gottman, he stated the need to investigate the quality of a marriage rather than just the status of it. This is because the quality of the marriage can have different impacts on the levels of stress that the workers may be experiencing. A happy may have a negative impact on stress, and an abusive marriage has the tendency to impose stress (Gottman, 1999).

In support of dominant research findings, this study revealed that older workers are less stressed than younger nurses (Siddiqui et al., 2017; Achour et al., 2019). Opposite to this, Götz et al. (2018) suggest that older nurses may be more stressed because younger workers have possibly different motivations to work than older workers. For example, younger workers may face higher pressure to develop strong workplace relationships, and therefore, they are more likely to continue working compared to their older counterparts, even if conditions at work are poor. The differences found in the various studies may be influenced by demography, culture, or time. Differences in sample sizes and, methodology and type of population may also affect the results, although the focus group is equal. Further research is needed to clarify how these factors can affect the study results.

The results of the study indicate that female and younger nurses experience high levels of stress. This implies that, these groups of nurses are more likely to report absenteeism, lateness and even turnover. Since they make up majority of the hospital's nursing stuff, productivity and quality healthcare giving is at risk. It is therefore important that healthcare organizations give weight to the need for prevention programs targeted at female and young nurses tailored to help them with stress management.

\section{Conclusion}

This study has presented and analyzed the results investigating the impact that individual differences have on the level of occupational stress in workers, taking gender, age and marital status into consideration. Although there was no significant association between all three variables and stress, there is no doubt that gender and age produce a significant impact on the level of stress of nurses. This will help inform managers and other stakeholders to put in place measures that respond to the individual differences of workers when managing stress, especially for nurses in the hospital. This can be in a form of segmented group therapy and special attention for special needs. It is recommended that: future studies will make provision for analyzing the quality of one's marriage as a measure of the impact of marriage on stress.

\section{Conflicts of Interest}

The authors declare no conflicts of interest regarding the publication of this paper. 


\section{References}

Abdulai, T. I. (2011). Occupational Stress in Healthcare Workers: The Case of the Goaso Government Hospital. Master's Thesis. Kumasi: Kwame Nkrumah University of Science and Technology Institute of Distance Learning.

Achour, M., Binti, I., Ghani, A., Marzuki, A., Isahak, B., Roslan, M., \& Nor, M. (2019). Job Stress and Nurses Well-Being: Prayer and Age as Moderators. Community Mental Health Journal, 55, 1226-1235. https://doi.org/10.1007/s10597-019-00410-y

Adzakpah, G., Laar, S. A., \& Fiadjoe (2016). Occupational Stress among Nurses in a Hospital Setting in Ghana. Clinical Case Reports and Reviews, 2, 333-338.

Alhassan, A. R., \& AduPoku, K. (2018). Experiences of Frontline Nursing Staff on Workplace Safety and Occupational Health Hazards in Two Psychiatric Hospitals in Ghana. BMC Public Health, 18, 701. https://doi.org/10.1186/s12889-018-5620-5

Alomani, Q. (2016). Causes and Effects of Occupational Stress in Nursing. Proceedings of 17th Iastem International Conference, Istanbul Turkey.

Amazue, L. O., \& Onyishi, I. E. (2016). Stress Coping Strategies, Perceived Organizational Support and Marital Status as Predictors of Work-Life Balance among Nigerian Bank Employees. Social Indicators Research, 128, 147-159.

https://doi.org/10.1007/s11205-015-1023-5

American Psychological Association (APA) (2010). Stress and Gender. https://www.apa.org/news/press/release/stress/2010/gender-stress

Ang, S. Y., Dhaliwal, S. S., Ayre, T. C., Uthaman, T., Fong, K. Y., Tien, C. E., Zhou, H., \& Della, P. (2016). Demographics and Personality Factors Associated with Burnout among Nurses in a Singapore Tertiary Hospital. BioMed Research International, 2016, Article ID: 6960184. https://doi.org/10.1155/2016/6960184

Bamboo, H. R. (2020). Grossary of Human Resources Management and Employee Benefit Terms. https://www.bamboohr.com/hr-glossary/occupational-stress

Baruch, G. K., Biener, L., \& Barnett, R. C. (1987). Women and Gender in Research on Work and Family Stress. American Psychologist, 42, 130-136.

Biswas, S., \& Naidu, S. (2019). A Study Correlate Perceived Stress with Marital Status in Working Men Women in Bengaluru City. International Journal of Psychology, 7, 212-215. https://doi.org/10.5958/2320-608X.2019.00172.0

Bublitz, S., Guido, L. A., Kirchhof, R. S., Neves, E. T., \& Lopes, L. F. (2015). Perfil Sociodemográfico Eacadêmico de Discentes de Enfermagem de Quarto Instituições Brasileiras. The Revista Gaúcha de Enfermagem, 36, 77-83.

https://doi.org/10.1590/1983-1447.2015.01.48836

Carr, J., Kelly, B., Keaton, R., \& Albrecht, C. (2011). Getting to Grips with Stress in the Workplace: Strategies for Promoting Healthier, More Productive Environment. $\mathrm{Hu}$ man Resource Management International Digest, 19, 32-38.

https://doi.org/10.1108/09670731111140748

Caruso, R., Miazza, D., Berzolari, F. G., Grugnetti, A. M., Lichosik, D., \& Arrigoni, C. (2017). Gender Differences among Cancer Nurses' Stress Perception and Coping: An Italian Single Centre Observational Study. GiornaleItaliano Di Medicina Del Lavoro Ed Ergonomia, 39, 93-99.

Cestari, V. R. F., Barbosa, I. V., Florêncio, R. S., Pessoa, V. M., \& Moreira, T. M. (2017). Stress in Nursing Students: Study on Sociodemographic and Academic Vulnerabilities. Acta Paulista de Enfermagem, 30, 190-196.

https://doi.org/10.1590/1982-0194201700029 
Cheng, T. C., Lo, C. C., \& Simpson, G. M. (2016). Marital Status and Work-Related Health Limitation: A Longitudinal Study of Young Adult and Middle-Aged Americans. International Journal of Public Health, 61, 91-100. https://doi.org/10.1007/s00038-015-0695-6

Dab, W., Temime, L., Jones, G., \& Hocine, M. (2015). Demographic and Occupational Predictors of Stress and Fatigue in French Intensive-Care Registered Nurses and Nurses' Aides: A Cross-Sectional Study. International Journal of Nursing Studies, 52, 250-259. https://doi.org/10.1016/j.ijnurstu.2014.07.015

Deguchi, Y., Iwasaki, S., Kanchika, M., Nitta, T., Mitake, T., Nogi, Y. et al. (2018) Gender Differences in the Relationships between Perceived Individual-Level Occupational Stress and Hazardous Alcohol Consumption among Japanese Teachers: A Cross-Sectional Study. PLoS ONE, 13, e0204248.

https://doi.org/10.1371/journal.pone.0204248

Duarte, J., \& Pinto-Gouveia, J. (2017). The Role of Psychological Factors in Oncology Nurses' Burnout and Compassion Fatigue Symptoms. European Journal of Oncology Nursing, 28, 114-121. https://doi.org/10.1016/j.ejon.2017.04.002

Ebrahimi, S., \& Kargar, Z. (2018). Occupational Stress among Medical Residents in Educational Hospitals. Annals of Occupational and Environmental Medicine, $30,51$. https://doi.org/10.1186/s40557-018-0262-8

Ezenwaji, I. O., Eseadi, C., Okide, C. C., Nwosu, N. C. et al. (2019). Work-Related Stress, Burnout, and Related Sociodemographic Factors among Nurses. Medicine (Baltimore), 98, e13889.

Faraji, A., Karimi, M., Azizi, S. M., Janatolmakan, M., \& Khatony, A. (2019). Occupational Stress and Its Related Demographic Factors among Iranian CCU Nurses: A Cross-Sectional Study. BMC Research Notes, 12, Article No. 634. https://doi.org/10.1186/s13104-019-4674-5

Franca, S. P., Martino, M. M., Aniceto, E. V., \& Silva, L. L. (2012). Preditores da Síndrome de Burnout emenfermeiros de serviços de urgênciapré-hospitalar.Acta Paulista de Enfermagem, 25, 68-73. https://doi.org/10.1590/S0103-21002012000100012

Fuente, C. G. A., Urquiza, J. L., Campos, E. M. et al. (2018a). Prevalence of Burnout Syndrome in Oncology Nursing: A Metaanalytic Study. Psychooncology, 27, 1426-1433. https://doi.org/10.1002/pon.4632

Fuente, G. A., Ortega, E., Ramirez, L., Solana, E. I., Vargas, C., \& Urquiza, J. L. (2018b). Gender, Marital Status, and Children as Risk Factors for Burnout in Nurses: A Meta-Analytic Study. International Journal of Environmental Research and Public Health, 15, 2102. https://doi.org/10.3390/ijerph15102102

Ghafoor, S., Chaudhry, S., \& Khan, J. S. (2020). Marital Status as a Stress Indicator in Postgraduate Dental Students. Journal of Pakistan Medical Association, 70, 158-161. https://doi.org/10.5455/JPMA.4571

Gottman, J. M. (1999). The Marriage Clinic: A Scientifically Based Marital Therapy. New York: W.W. Norton \& Company.

Götz, S., Hoven, H., Müller, A., Dragano, N., \& Wahrendorf, M. (2018). Age Differences in the Association between Stressful Work and Sickness Absence among Full-Time Employed Workers: Evidence from the German Socio-Economic Panel. International Archives of Occupational and Environmental Health, 91, 479-496. https://doi.org/10.1007/s00420-018-1298-3

Health and Safety Executive (2015). Work Related Stress, Anxiety and Depression Statistics in Great Britain. National Statistics. http://www.hse.gove.uk/statistics 
Heathfied, S. M. (2019). Understanding Stress and How It Affects the Workplace. Human Resource, the Balance Careers.

Hernández, P. L., Ariza, T., Urquiza, G. J. L. et al. (2018). Prevalence of Burnout in Paediatric Nurses: A Systematic Review and Meta-Analysis. PLoS ONE, 13, e0195039. https://doi.org/10.1371/journal.pone.0195039

Hipp, M., Pilz, L., Al-Batran, S. E., Hautmann, M. G., \& Hofheinz, R. (2015). Workload and Quality of Life of Medical Doctors in the Field of Oncology in Germany-A Survey of the Working Group Quality of Life of the AIO for the Study Group of Internal Oncology. Oncology Research and Treatment, 38, 154-159. https://doi.org/10.1159/000381074

Howells, M. E., Dancause, K., Pond Jr., R., Rivera, L., Simons, D., \& Alston, B. D. (2020). Maternal Marital Status Predicts Self Reported Stress among Pregnant Women Following Hurricane Florence. American Journal of Human Biology, e23427. https://doi.org/10.1002/ajhb.23427

Huang, L., Lin, G., Tang, L., Yu, L., \& Zhou, Z. (2020). Special Attention to Nurses' Protection during the COVID-19 Epidemic. Critical Care, 24, 120. https://doi.org/10.1186/s13054-020-2841-7

Jacobs, A. W., Hill, T. D., Tope, D., \& O’Brien, L. K. (2016). Employment Transitions, Child Care Conflict, and the Mental Health of Low Income Urban Women with Children. Women's Health Issues, 26, 366-376. https://doi.org/10.1016/j.whi.2016.05.003

Jourdain, G., \& Chênevert, D. (2010). Job Demands-Resources, Burnout and Intention to Leave the Nursing Profession: A Questionnaire Survey. International Journal of Nursing Studies, 47, 709-722. https://doi.org/10.1016/j.ijnurstu.2009.11.007

Kashif, M., \& Khan, T. M. (2016). Level of Stress and Its Association with Socio-Demographic Factors among Students of Allied Health Sciences. Journal of Rawalpindi Medical College Students Supplement, 20, 27-30.

Khosravi, M., \& Kasaeiyan, R. (2019). The Predictive Role of Socio-Demographic Characteristics, Job Stress and Psychological Hardiness in Job Satisfaction of Nurses. Journal of Advanced Pharmacy Education \& Research, 9, 174-178.

Kohen, Y. I., \& Kaplan, O. (2016). Traumatic Stress during Population Wide Exposure to Trauma in Israel: Gender as a Moderator of Marital Status and Social Support. Stress and Health, 32, 636-640. https://doi.org/10.1002/smi.2647

Kokoroko, E., \& Sanda, M. A. (2019). Effect of Workload on Job Stress of Ghanaian OPD Nurses: The Role of Coworker Support. Safety and Health at Work, 10, 341-346. https://doi.org/10.1016/j.shaw.2019.04.002

Lee, J., \& Cho, Y. H. (2016). Gender Differences in Job Stress and Stress Coping Strategies among Korean Nurses. International Journal of Bio-Science and Bio-Technology, 8, 143-148. https://doi.org/10.14257/ijbsbt.2016.8.3.15

Liu, L., Xu, X., Wu, H., Yang, Y., \& Wang, L. (2015). Association of Psychological Capital Demographics and Occupational Factors with Cigarette Smoking among Chinese Underground Miners. BMC Public Health, 15, 20.

https://doi.org/10.1186/s12889-015-1349-6

Makhaita, H. M. Al, Sabra, A. A., \& Hafez, A. S. (2014). Predictors of Work-Related Stress among Nurses Working in Primary and Secondary Health Care Levels in Dammam, Eastern Saudi Arabia. Journal of Family \& Community Medicine, 21, 79-84.

https://doi.org/10.4103/2230-8229.134762

Mark, G., \& Smith, A. P. (2012). Occupational Stress, Job Characteristics, Coping, and the 
Mental Health of Nurses. British Journal of Health Psychology, 17, 505-521. https://doi.org/10.1111/j.2044-8287.2011.02051.x

Masa'Deh, R., Jarrah, S., \& Mohannad, E. A. (2018). Occupational Stress in Psychiatric Nursing. International Journal of Africa Nursing Sciences, 9, 115-119. https://doi.org/10.1016/j.ijans.2018.10.001

Mediline Plus (2020). U.S National Library of Medicine, Department of Health and Human Service. http://medilineplus.gov/ency/article/00321.htm\#start

Moustaka, M., \& Constantinidis, T. C. (2010). Sources and Effects of Work-Related Stress in Nursing. Health Science Journal, 4, 210-216.

Mudallal, R. H., Othman, W. M., \& Hassan, N. F. Al. (2017). Nurses “Burnout”: The Influence of Leader Empowering Behaviors, Work Conditions, and Demographic Traits. INQUIRY: The Journal of Health Care Organization, Provision, and Financing, 54. https://doi.org/10.1177/0046958017724944

Nam, Y., Kwon, S. C., Lee, Y. et al. (2018). Relationship between Job Stress and Functional Dyspepsia in Display Manufacturing Sector Workers: A Cross Sectional Study. Annals of Occupational and Environmental Medicine, 30, 62.

https://doi.org/10.1186/s40557-018-0274-4

Nursing Times March 2008. http://www.nursintimes.net/archive/why-are-there-so-few-men-in-nursing-03-03-2008

Nyamwata, J., Kokonya, D., Odera, P., \& Sanga, P. K. (2017). Prevalence of Depression and Related Socio Demographic Factors among Nurses Working at Moi Teaching and Referral Hospital, Uasin Gishu County, Eldoret. Journal of Psychiatry \& Mental Disorders, $2,1007$.

Onasoga, O. A., Ogbebor, S., Osamudiamen, \& Ojo, A. A. (2013) .Occupational Stress Management among Nurses in Selected Hospital in Benin City, Edo State, Nigeria. European Journal of Experimental Biology, 3, 473-481.

Park, S. A., \& Ahn, S. H. (2015). Relation of Compassionate Competence to Burnout, Job Stress, Turnover Intention, Job Satisfaction and Organizational Commitment for Oncology Nurses in Korea. Asian Pacific Journal of Cancer Prevention, 16, 5463-5469. https://doi.org/10.7314/APJCP.2015.16.13.5463

Picakciefe, M., Turgut, A., Igneci, E., Cayli, F., \& Deveci, A. (2015). Relationship between Socio-Demographic Features, Work-Related Conditions, and Level of Anxiety among Turkish Primary Health Care Workers. Workplace Health \& Safety, 63, 502-511. https://doi.org/10.1177/2165079915593249

Qian, Y., Fan, W., Men and Women at Work (2019). Occupational Gender Composition and Affective Well-Being in the United States. Journal of Happiness Studies, 20, 2077-2099. https://doi.org/10.1007/s10902-018-0039-3

Reyes, C. S., Luis, C. C., \& Urquiza, G. J. L. (2018). Burnout Syndrome and Its Prevalence in Primary Care Nursing: A Systematic Review and Meta-Analysis. BMC Family Practice, 19, 59. https://doi.org/10.1186/s12875-018-0748-Z

Romano, M., Festini, F., \& Bronner, L. (2015). Cross-Sectional Study on the Determinants of Work Stress for Nurses and Intention of Leaving the Profession. Publication Information, 68, 203-210.

Sabzi, Z., Royani, Z., Mancheri, H., Aghaeinejad, A., Kochaki, M., \& Kalantari, S. (2017). Predictors of Job Stress among Critical Care Nurses. IOH, 14, 45-52.

Sayeed, S., Thokchom, S., \& Sarkar, S. (2017). Assessment of Gender Differences in Stress at Work Place and Psychiatric Morbidity among Staff Nurses. International Journal of Applied Research, 3, 560-563. 
Sharafi, H., Gholami, P., Sadeghi, S., Ghorbani, M., \& Rezaei, F. (2018). Job Stress and Related Factors among Staff of the Operation Room in Bandar Abbas. Iranian IJRN, 4, 29-34.

Shukla, A., \& Srivastava, R. (2016). Examining the Effect of Emotional Intelligence on Socio-Demographic Variable and Job Stress among Retail Employees. Cogent Business \& Management, 3, Article ID: 1201905. https://doi.org/10.1080/23311975.2016.1201905

Siddiqui, A. F., Ahmed, M., Zaalah, A., Alqahtani, A. A., \& Alqahtani, M. A. S. (2017). Perceived Stress and Its Associated Sociodemographic Factors among Physicians Working in Aseer Region of Saudi Arabia. Journal of the Liaquat University of Medical and Health Sciences, 16, 10-16. https://doi.org/10.22442/jlumhs.171610498

Soltan, M. R., Al-Hassanin, S. A., Soliman, S. S., \& Gohar, S. F. (2020). Workplace-Related Stress among Oncologists: Egyptian Single-Centered Observational Study. Middle East Current Psychiatry, 27, Article No. 19. https://doi.org/10.1186/s43045-020-00026-Z

Taleghani, F., Ashouri, E., \& Saburi, M. (2017). Empathy, Burnout, Demographic Variables and Their Relationships in Oncology Nurses. Iranian Journal of Nursing and Midwifery Research, 22, 41. https://doi.org/10.4103/ijnmr.IJNMR 6616

Trousselard, M., Dutheil, F., Naughton, G., Cosserant, S., Amadon, S., Dualé, C., \& Schoeffler, P. (2015). Stress among Nurses Working in Emergency, Anesthesiology and Intensive Care Units Depends on Qualification: A Job Demand-Control Survey. International Archives of Occupational and Environmental Health, 89, 221-229. https://doi.org/10.1007/s00420-015-1065-7

Urquiza, G. J. L., Fuente, S. E. I., \& García, L. (2017). Prevalence of Burnout Syndrome in Emergency Nurses: A Meta-Analysis. Critical Care Nurse, 37, e1-9. https://doi.org/10.4037/ccn2017508

Urquiza, J., López, A., \& Solana, E. (2016). Prevalence, Risk Factors, and Levels of Burnout among Oncology Nurses: A Systematic Review. Oncology Nursing Forum, 43, E104-E120. https://doi.org/10.1188/16.ONF.E104-E120

Wang, Y., Jiao, Y., Nie, J., O’Neil, A., Huang, W., \& Zhang, L. (2020). Sex Differences in the Association between Marital Status and the Risk of Cardiovascular, Cancer, and All-Cause Mortality: A Systematic Review and Meta Analysis of 7,881,040 Individuals. Global Health Research and Policy, 5, 4. https://doi.org/10.1186/s41256-020-00133-8

Yamane, T. (1967). Statistics, an Introductory Analysis (2nd ed.). New York: Harper and Row.

Yim, H.-Y., Seo, H.-J., Cho, Y., \& Kim, J. (2017). Mediating Role of Psychological Capital in Relationship between Occupational Stress and Turnover Intention among Nurses at Veterans Administration Hospitals in Korea. Asian Nursing Research, 11, 6-12. https://doi.org/10.1016/j.anr.2017.01.002

Young Kim, S., Shin, D. W., Seon, K., Kim, J., Yang-Ri, P., Shin, Y. H., \& Won Lim, S. (2017). Gender Differences and Occupational Stress Associated with Suicide Ideation among South Korean Employees: The Kangbuk Samsung Health Study. Psychiatry Investigation, 15, 156-163. https://doi.org/10.30773/pi.2017.05.31.1 